\title{
GDC registration coming your way
}

For the first time in history the

General

Dental

Council is

opening

its doors to

the entire

clinical

team,

reports

Arveen

Bajaj.

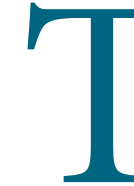

$\begin{array}{ll}\text { he UK dental team is facing one } & \text { It does this by keeping up-to-date lists of } \\ \text { of its most far-reaching } & \text { properly qualified dentists, dental hygienists }\end{array}$

It does this by keeping up-to-date lists of changes in its history with the and dental therapists, setting high standards expansion of General Dental of dental practice and conduct, maintaining Council (GDC) registration. In high standards of dental education, requiring of dental nurses, dental dentists to take part in continuing profes ental technicians, al development (CPD) to keep their knowand od sesthetists and technologists edge and skills up-to-date and taking action if by the registration, which is will be affected there is doubt abe allowed to continue practistime in 2004 . But many wo

know, if dental teams

des without being regis- given to it by Parliament - cover all registered, why start now? ing dentistry.

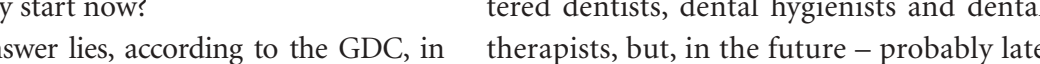
not only better protection for the thousands of 2004 - they will apply to all registered patients seen in surgeries all over the UK, but PCDs. It will then be compulsory for dental in dental teams gaining proper recognition of nurses, dental technicians, clinical dental their professional status and responsibility. technicians, maxillofacial prosthetists and As the regulatory body of the dental pro- technologists and orthodontic therapists to fession, the GDC's role is to protect patients. register with the GDC.
'PCDs will gain proper recognition of their professional status and responsibilitie 


\section{Being on the register}

will mean a number of things for the registrant. According to the GDC, by having a register the standard of education received by all members of the dental team can be guaranteed, and PCDs will gain proper recognition of their professional status and responsibilities. They will also benefit from improved educational and training opportunities

This guaranteed standard of education being received will then increase protection for the public, helping them feel confident in all members of the dental profession and will also mean that PCDs will be responsible and accountable for their actions.

As the titles 'dental hygienist', 'dental therapist', 'dental nurse', 'dental technician', 'clinical dental technician', 'maxillofacial prosthetist and technologist' and 'orthodontic therapist' will be reserved by law for those PCDs who become registered, anyone wishing to use these titles will have to be registered with the GDC, otherwise they will be breaking the law.

What you need to join the register The GDC asserts that entry onto the PCD register will be on the basis of training and approved qualifications recognised and regulated by it. However, for a period of two years from the opening of the register in 2004, PCDs who do not have recognised qualifications but have experience or have previously awaded quifections, wil be so to

So, if you are a UCD who had years of expent the bou are not aligis, to does not When the PCD register op ess the rill be Wo-year 'tanitional perid' during whe PCDs can andy under dese cong whe the GDC will assess whether or not your training and experience eqd you to cary training and experience equip you

Dental nurses will need four years fullDexperience in the past eight years oullpart-time equivalent and dental technicians will need seven years full-time experience or the part-time equivalent.

After the end of the two-year 'transition period', the GDC makes it clear that PCD will not be able to join the register based on experience alone, as they will need the approved qualification. They recommend that those who do not have qualification should apply for registration as soon as the PCD register opens next year.
Dental nurses and dental technicians who are members of the Voluntary Nationa Registers for their professions will be eligible to join the PCD register and maxillofacia prothesthists and technologists who are full members of the Institute of Maxillofacial Prothesthic
gible to join

Once registered, PCDs will be able to practise dentistry to the extent taught during their training and any treatment carried out by a PCD must be prescribed by a dentist who has be responsible to the GDC for practising within the limits of their competen

\section{Cost and training}

The GDC will be charging PCDs an annua retention fee in order to ren ister and to be allowed to keep practisin though as yet it has not decided what the fee will be. It also states that keeping skills an knowledge up-to-date is an integral part o professional accountability and plans to introduce a compulsory minimum numb of hours of continual professional development (CPD) for PCDs, but the details of this ave yet to be established.

There is also a committee which make decisions on dental professionals' fitness to practise. The Fitness to Practice panel is drawn from an independent pool of dental professionals and lay people. When it receives a complaint about someone on its registers, the GDC investigates complaints abot the profssional condus or finess to practse of dentists or PCDs and has the

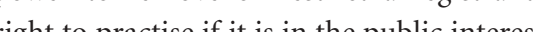
Once PCDs have registered, the GDC Once PCDs he ther to issue guidance to registants on xpect PCDs to abide by. Registrants will he responsibe to the GDC for practisthe responsibe to the GDC for practisand dentists, as leaders of the dental term will be responsible to the GDC for asuring that members of the dental team are not sked to undertake tasks that go beyon their training and skills.

The GDC does not know when in 2004 the register will open as new legislation is needed to make this possible. It intends to publicise when PCDs can apply for entry to the PCD register as soon as it is finalised and will contact all registered dentists and professional associations to let them know. Statutory registration will not yet exten to practice managers and receptionists as the categories of $\mathrm{PCD}$ who have vement with patients. Althoug there are currently no plans to register practice managers and receptionists this is something that the GDC may consider again once the $\mathrm{PCD}$ register opens.

Information on PCD registration is available on the GDC website at www.gdc-uk.org hich has full details about qualifications, curricula requirements for qualification and experience needed for entry onto the register. The GDC is also holding 'PCD oadshows' around the country from now these is also on the GDC website - and all members of the dental team are encouraged to attend.

\section{WHAT IS A PCD?}

PCD stands for Professionals Complementary to Dentistry and - Dental nurses including orthodontic

- Dental hygienists Dental technicians including clinical and orthodontic technicians - Dental therapists including - Practice Manage - Maxillofacial Prosthetists an Technologists Not all PCDs will be required to register with the GDC. See main article for details.

Qualifications needed to register with the GDC

Dental Nurse: Either the NVQ/SVQ Level 3 in Oral Healthcare or the Nation Cerrficate in Denta Nursing or Certificate of Proficiency in Denta $\mathrm{NuSh}$ by a dental hospital which is recognised by the association of Dental Hospitals.

Clinical Dental Technician: No qualification currently exists in the UK. Qualifications for Clinical Dental Technicians have vet to be considered and approved by the Council.

Dental Technician: BTEC National Diploma in Dental Technology, SQA higher 列 Manchester Metropolitan University or the University of Wales Institute, Cardiff

Orthodontic Therapist: No qualification currently exists in the UK. Quallifications Orthodontic Therapists have yet to be considered and approved by the Council Maxillofacial Prosthetist and Technologist: Need to be quallified with one of the following in order to register: HNC/D inclualing four maxillofacial options IMPT Qualifying Examination, Diploma in Professional Studies (Maxillofacial) - Hospital in Professional Studies, Manchester Metropolitan University

Dental Hygienist: One from the following list of qualifications, Diploma in Dente Hygiene or combined Diploma in Dental Hygiene and Dental Therapy (awarded by the School of Dental Hygiene/Hygiene and Therapy or the Royal College of Surgeons)

Dental Therapist: Qualifications currently approved for enrolment are the Diploma in Dental Therapy or combined Diploma in Dental Hygiene and Denta Terapy (awarded by Schools of Dental Hygiene and Dental Therapy).

Other qualifications which are no longer awarded will also make you eligible for

Overseas PCDs: The GDC will establish arrangements for PCDs with Europec qualifications to apply for registration and set up a system of competency tests for those trained outside Europe. 